"This accepted author manuscript is copyrighted and published by Elsevier. It is posted here by agreement between Elsevier and MTA. The definitive version of the text was subsequently published in [Computers in Human Behavior, 59, pp.411-419, doi:10.1016/j.chb.2016.02.043]. Available under license CC-BY-NC-ND."

\title{
Humans attribute emotions to a robot that shows simple behavioural patterns borrowed
} from dog behaviour

\begin{abstract}
In social robotics it has been a crucial issue to determine the minimal set of relevant behaviour actions that humans interpret as social competencies. As a potential alternative of mimicking human abilities, it has been proposed to use a non-human animal, the dog as a natural model for developing simple, non-linguistic emotional expressions for non-humanoid social robots. In the present study human participants were presented with short video sequences in which a PeopleBot robot and a dog displayed behaviours that corresponded to five emotional states (joy, fear, anger, sadness, and neutral) in a neutral environment. The actions of the robot were developed on the basis of dog expressive behaviours that had been described in previous studies of dog-human interactions. In their answers to open-ended questions, participants spontaneously attributed emotional states to both the robot and the dog. They could also successfully match all dog videos and all robot videos with the correct emotional state. We conclude that our bottom up approach (starting from a simpler animal signalling system, rather than decomposing complex human signalling systems) can be used as a promising model for developing believable and easily recognisable emotional displays for non-humanoid social robots.
\end{abstract}

\section{Highlights:}

Humans spontaneously attribute emotions to an ethologically inspired robot 
Dog emotional videos prime the attribution of emotions to robot videos

Participants were able to match both dog and robot videos to the corresponding emotions Experience with dogs does not help identify dog and robot emotions

Keywords: robot emotions; ethological approach; dog model; expressive behaviour 


\section{Introduction}

In order to make humans perceive interactions with a social robot as more natural and less disturbing, it is essential for the robot to act in accordance with the given social situation and show relevant emotions (Bartneck, Reichenbach, \& Breemen, 2004; Leite, Martinho, \& Paiva, 2008), although in some cases emotion expression of a robot might lead to its poorer perception by humans (Petisca, Dias, \& Paiva, 2014). While there are some data on decoding emotions based on body language and vocal signals in humans (Bänziger, Grandjean, \& Scherer, 2009; Chuenwattanapranithi, 2008; de Gelder, 2009), so far the vast majority of studies on emotion recognition have focused on facial expressions (see e.g. Breazeal, 2003; Ekman, 1993). In robotics, up to now human behaviour and facial expressions have constituted the basis for developing autonomous expressive behaviours in artificial agents (e.g. facial expressions: Bartneck, 2001; Cañamero \& Fredslund, 2000; Kätsyri, Klucharev, Frydrych, \& Sams, 2003; posture: Erden, 2013; gestures: Li \& Chignell, 2010). The ability to converse is also regarded as one of the main design requirements (e.g. Li, Yeow, \& Tan, 2011), even though the communication of basic emotional states by non-linguistic behaviours (see above) plays an important role also in humans. A well-known social robot, Kismet, for example displayed a range of emotive expressions not exclusively through facial expressions, but also using body posture and gaze direction (Breazeal, 2002), as well as quality of voice (Breazeal, 2003). Recently it has been shown that even a posture as simple as a head tilt might influence human attributions of complex properties such as warmth, eeriness, attractiveness, and dominance (Mara \& Appel, 2015).

Considering the abilities and limitations of most present-day autonomous social agents, it seems that presenting relevant human-like facial expressions pose huge difficulties for them. Most importantly, the majority of social robots do not need verbal abilities or a human-like face to fit their original function (e.g. assistant robot for the elderly: Pineau, 2003; or for office purposes: Severinson-Eklundh, Green, \& Hüttenrauch, 2003). Although facial 
expressions provide important cues for communicating emotional states, based on mammalian homologies humans possess an evolutionarily more ancient behavioural system that expresses changes in the inner state by means of the whole body. Furthermore recent studies support the claim that humans recognize/identify some basic emotional states based on simple behavioural displays in several animal species (Morris, Fidler, \& Costall, 2000; Waller, Bard, Vick, \& Smith Pasqualini, 2007), however, in these cases human participants tend to capitalize also on the context of the observed expressive behaviours (e.g. Aviezer et al., 2009; Meeren, van Heijnsbergen, \& de Gelder, 2005). Besides facial expressions, simple arm movements can convey emotions in humans (Gross, Crane, \& Fredrickson, 2010; Wallbott, 1998). However it does not seem practical to add extra non-functional features, such as "arms and hands" (which would work reliably under field conditions) to autonomous social robots just for displaying some emotional expressions (like raising it, lowering it etc.), because this would make the robot unnecessarily expensive.

Based on the above considerations, it has been suggested that the human-robot interaction should be viewed as an interspecific interaction (between two different species) that requires successful communication, and propose using a non-human species, in this concrete example the dog, as a potential natural model for developing social robots and human-robot interactions (see in detail: Miklósi \& Gácsi, 2012).

There have been some attempts to use animals or even fictional characters as models for social robots, but these studies aimed to replicate the animals' emotional expression by designing a robot with the same embodiment. For example, the AIBO (Friedman, Kahn, \& Hagman, 2003) robot had all the main body features, as well as degrees of freedom in movement that are necessary for the reproduction of many dog specific behaviours, including some emotional expressions. Our approach is different because we assume that in practice most social robots that humans need to interact with would not have an animal-like (or 
human-like) embodiment because the body and capabilities of the robots would be tuned to the functional requirements in order to make the robot useful and less expensive.

The dog is a good candidate for being a non-human model for social robotics as its behaviour is increasingly well-known (Bensky, Gosling, \& Sinn, 2013; Morell, 2009) and as due to the shared social environment of dogs and humans in the course of domestication, the social competence (social skills that conform to the expectations of others and the social rules of the group) between humans and dogs is exceptional (Miklósi \& Topál, 2013; Topál et al., 2009). Dogs are able to develop individual attachment relationship with humans even in adulthood (Gácsi, Topál, Miklósi, Dóka, \& Csányi, 2001; Valsecchi, Previde, Accorsi, \& Fallani, 2010), follow referential pointing gestures provided by humans (Kaminski, Bräuer, Call, \& Tomasello, 2009; Soproni, Miklósi, Topál, \& Csányi, 2002), are capable of social referencing (Merola, Prato-Previde, \& Marshall-Pescini, 2012) as well as have different personalities resembling human personality types (Gosling, Kwan, \& John, 2003; Turcsán, Range, Virányi, Miklósi, \& Kubinyi, 2012). For the current study it is especially important to point out that dogs can successfully communicate and cooperate with humans that is they show social behaviours that humans can easily understand without massive prior learning (dogs' showing behaviour: Miklósi, Polgárdi, Topál, \& Csányi, 2000; children recognise emotional content of dog barks: Pongrácz, Molnár, Dóka, \& Miklósi, 2011; disabled people recognise assistance dogs' conflict behaviour: Gácsi, Szakadát, \& Miklósi, 2013; similarities in the emotion processing at the neural level in dogs and humans: Andics, Gácsi, Faragó, Kis, \& Miklósi, 2014), and most importantly, dog owners tend to attribute complex emotions to their pets (secondary emotions: Morris, Doe, \& Godsell, 2008; guilt: Hecht, Miklósi, \& Gácsi, 2012).

The dog has already been successfully applied as the prototype of non-human companions in human-robot interaction research (Ichikawa et al., 2012; Koay et al., 2013; Kovács, Vincze, Gácsi, Miklósi, \& Korondi, 2009; Lakatos, Gácsi, et al., 2014; Syrdal, Koay, Gácsi, 
Walters, \& Dautenhahn, 2010). Social robots are designed to actively interact with humans and, similarly to dogs, they need to fulfil double criteria: i) successful performance of the actions necessary for their specific function (i.e. providing assistance for the elderly or disabled persons, guiding visitors in museums, etc.), and ii) showing believable social/communicative abilities during interactions with the human users. During the process of domestication the dog adapted to the human environment and acquired or expanded the competencies necessary to fulfil the second criteria. With respect to the functions, dog breeds were selected to fit specific purposes to assist human activities (hunting, herding, etc) and dogs can be trained to provide efficient help for disabled people (guide dogs, assistance dogs, hearing dogs, etc.). It seems that in a broad sense, social robots and assistance dogs would soon play rather similar roles in the human environment (Gácsi et al., 2013). Considering all the above arguments, rather than relying on a top down approach trying to simplify human emotional expressions in order to project them on a rather clumsy robotic embodiment, we prefer to start from a simpler set of emotional behaviour and the dog offers a good candidate for this.

The dog should be seen as a representative of social mammals which show a wide range of emotional behaviours. Its embodiment represents a very conservative mammalian situation in which emotional behaviour is dispersed over the whole body, but at the same time it is also less sophisticated than that of humans. The dog model offers the possibility of creating emotional expressions without the need for adding specific, otherwise non-functional features to social robots.

Humans' success in identifying dogs' expressive behaviours and their tendency to credit dogs with inner states seems to be irrespective of their previous experience with dogs (video clips of body movements - Tami \& Gallagher, 2009; photographs of facial expressions Bloom \& Friedman, 2013). Considering the acoustic modality, human participants have been shown to rely on the same rules when they assess the emotional valence of human and dog 
vocalizations (Faragó, Andics, et al., 2014). Moreover, humans with different levels of experience with dogs described the emotional content of bark sequences quite similarly (Pongrácz, Molnár, Miklósi, \& Csányi, 2005). Due to the redundant nature of dogs' expressive behaviours in different modalities (movements, posture, vocalization, signallers such as ear set, tail carriage, and change in size such as crouching or piloerection of the hair, etc. - e.g., Fox, 1971), we suggest that it is possible to extract relevant behavioural actions from this rich repertoire for social robots of different embodiments and functions.

The PeopleBot robot used in this experiment had a markedly different embodiment compared to dog morphology (see Figure 1), moreover it had a clearly mechanistic appearance lacking a human-like face and verbal abilities. In order to avoid the influence of the social context that had been shown to play a crucial role in interpreting emotional states (e.g. Carroll \& Russell, 1996), our stimuli were recorded in a neutral laboratory environment.

This experiment was designed to be one of the first steps of our investigation, testing whether even simple expressions of emotional behaviours can bring about acceptable level of emotion attribution to a robot in the human observers. This is important because such findings could decrease the need to rely on the complexities of human emotion expressions in social robot development. In this concrete experiment, we studied whether the relatively simple expressive emotional behaviours of dogs can be re-configured for a relatively common robotic embodiment offered by Peoplebot.

We hypothesized that in an open-ended questionnaire participants would spontaneously attribute inner states both to a robot and a dog, after viewing short video sequences where they display actions based on dogs' basic expressive behaviours compared to similar video clips showing neutral behaviours.

Our further assumption was that participants would attribute corresponding emotions to the dog and the robot if they could choose from a set of inner states, and that their certainty ratings would correlate with the proportion of the correct responses. 
We expected, however, that the recognition of the emotion content of the dog videos could be easier.

Based on this assumption, we hypothesised that the presentation order of the robot and dog videos would have an impact on the responses, because realising the emotion displayed by the dog may help some participants to recognise later similar emotions in the case of the robot.

We further assumed that dog owners would be able to better recognise the emotional content of the dog video clips.

The occurrence of the correct answers in the open-ended and the multiple-choice questions was compared in order to test our hypothesis that the two questionnaires provide a consistent result.

\section{Method}

\subsection{Participants}

Our participants ( $N=81,53$ females and 28 males, from an age range of 18-26 years) were unpaid volunteers recruited from university students of different majors (biology, engineering, economy). We ensured that participants would be blind to the purpose of the study by contacting them personally visiting small courses at different universities, so none of them registered to the test on his/her own. Three participants did not complete the open-ended questionnaire (see later), thus the sample size for this part of the study was $\mathrm{N}=78$.

From these participants 39 were dog owners. The experimenter did not give the participants any specific information during the test.

\subsection{Robot and dog}


The robot used in this study was a PeopleBot research platform manufactured by the MobileRobots Inc (see on Figure 1). It was built on a robust differential-drive P3-DX wheeled mobile platform which was able to turn/spin in-place and navigate inside indoor environments. The robot base had a chest-level extension with a touch-screen mounted on its top. The PeopleBot could not alter its body posture or its size. The monitor mounted on the platform could be considered as a head in the sense that it had a front and a back side (so could indicate orientation), but it could not be moved independently from the body, and had no face or eyes. Two arms were fitted on the sides of the 'body'. One of them was a robotic arm (with five degrees of freedom) designed at the Wroclaw University of Technology. It consisted of two links and a hand formed of four fingers. A non-movable arm mock-up was mounted on the other side of the 'body' (on account of another experiment - Lakatos et al., 2014 - white gloves were fixed on the hands). The robot was able to emit pre-recorded sounds. The control system consisted of an efficient industrial PC running under Ubuntu Linux with real time Xenomai (http://www.xenomai.org), Player/Stage communication framework infrastructure and software implementing robot control algorithm (http://playerstage.sourceforge.net/).

The dog acting on the videos was a 3-year-old male Belgian malinois trained with food reward and social reinforcement, who was able to display specific behaviour actions responding to human signals. These actions were resulted partly by the dog's actual emotional state evoked by the owner's communication (e.g., tone of voice), and partly by the commands he followed, similarly to a human actor at the stage.

\subsection{Establishment of the emotional behaviours}

Based on a meta-analysis of previous studies (see below) we described dogs' emotional behaviours in both visual and acoustic modalities in simple social situations. We prepared a detailed list of the relevant behaviours for four basic emotional states; joy, sadness, anger, fear 
(Ekman, 1992; Jack, Garrod, \& Schyns, 2014; Plutchik, 2001), and used a neutral state as a control. We derived the basic emotional behaviours from observations of previous ethological studies of pet dogs in situations when a) dogs were observed in an emotion evoking context, b) the direction and speed of dogs' movements, changes in their postures and the position of body parts, and vocalisations could be assessed. The following concrete contexts were adopted: Joy: 'greeting the owner' (Konok, Dóka, \& Miklósi, 2011; Topál, Miklósi, Csányi, \& Dóka, 1998), and 'going for a walk' (Pongrácz et al., 2005); Anger: 'facing a threatening stranger' (Vas, Topál, Gácsi, Miklósi, \& Csányi, 2005), 'watching a stranger through the fence' (Pongrácz et al., 2011); Fear: 'facing a threatening stranger' (Klausz, Kis, Persa, Miklósi, \& Gácsi, 2014); Sadness: 'separation from owner' (Pongrácz et al., 2011; Topál et al., 1998), 'being scolded by owner' (Hecht et al., 2012); Neutral: 'mobile owner' task during which the owner moves around in a room without initiating interaction with or looking at the dog (Faragó, Miklósi, Korcsok, Száraz, \& Gácsi, 2014).

\subsection{Preparation of the video material}

In case of the robot, the actions were adjusted to the limitations of its embodiment. Due to the constraints of the recording context we could not apply each behaviour element for the dog either (e.g. the dog could not fully approach the trainer in case of the joy clip that was to be based on a greeting situation).

We prepared five short video clips with the robot (duration: 9-14 sec) and five clips with the dog (duration: 8-14 sec) displaying the emotional behaviours corresponding to the five inner states. Both the actions of the dog and the robot were recorded from the viewpoint of an observing human in the same laboratory, so that the acting dog and robot seemed to react to the viewer. During the video recordings, the robot was remotely controlled (by MJ and RM) through a dedicated remote operator interface which enabled simultaneous control of the robot base and the arm movements. For the recording of the dog clips, the trainer (MG) 
controlled the dog's actions from behind the camera, so the dog reacted to the trainer's signals in a way that he showed the expressive behaviours towards the camera.

We used pre-recorded artificial sound (PCM wav file) as the robots' vocalization. The original sound of the robot (R2D2 like short chirps) was modified and saved as separate files by using Praat (Boersma \& Weenink, 2014) in a way that their acoustic parameters followed the Morton rules (Morton, 1977) similarly to dog barks (Pongrácz, Molnár, \& Miklósi, 2006): the aggressive sound was low pitched, noisy and fast pulsing, the joyful sound had raised pitch, was less noisy and was fast pulsing, and the sad sound was elongated, slow pulsing, moderately noisy with a decreasing pitch. On the dog videos the original sound of the dog was used except in case of 'sadness' where the voice of another dog was dubbed onto the recording. In the case of fear and neutral clips no sound was applied, because based on our above mentioned meta-analysis, vocalisation was not or rarely produced in these contexts. The video clips were uncut, and slightly varied in length depending on the actions and speed of the dog and the robot. In Table 1 we summarize the major behaviours depicted on the videos (without describing subtle movements and dynamics).

Table 1

\begin{tabular}{|c|c|c|c|}
\hline & Dog behaviour & Robot behaviour & $\begin{array}{l}\text { Vocalization } \\
\text { in both dog } \\
\text { and robot }\end{array}$ \\
\hline \multirow{3}{*}{ JOY } & approaches & approaches & \multirow{3}{*}{$\begin{array}{l}\text { high-pitched, } \\
\text { tonal, staccato }\end{array}$} \\
\hline & wags his tail & lifts one arm, moves fingers & \\
\hline & sidles & partly spins & \\
\hline \multirow{3}{*}{ FEAR } & approaches crawling & approaches slowly & \multirow{3}{*}{-} \\
\hline & hanging ears, licks lips & backs & \\
\hline & turns, goes away & turns away, goes away & \\
\hline
\end{tabular}




\begin{tabular}{|c|c|c|c|}
\hline \multirow{3}{*}{ NEUTRAL } & turns toward viewer & turns toward the viewer & \multirow{3}{*}{-} \\
\hline & approaches (some wagging) & approaches & \\
\hline & stops, orients at viewer & stops, orients at viewer & \\
\hline \multirow{4}{*}{ SADNESS } & sits down & backs & \multirow{4}{*}{$\begin{array}{l}\text { low-pitched, } \\
\text { moderately } \\
\text { noisy, long- } \\
\text { drawn }\end{array}$} \\
\hline & lies down & turns away & \\
\hline & lays his head down & lowers its arm & \\
\hline & stays motionless & stays motionless & \\
\hline \multirow{3}{*}{ ANGER } & approaches (crawling) & approaches & \multirow{3}{*}{$\begin{array}{l}\text { low-pitched, } \\
\text { noisy, } \\
\text { loud, } \\
\text { staccato }\end{array}$} \\
\hline & wags his tail & moves its arm high & \\
\hline & $\begin{array}{l}\text { moves head up and down } \\
\text { dynamically (barking), } \\
\text { shows teeth }\end{array}$ & swings arm several times & \\
\hline
\end{tabular}

As an example, Figure 1 illustrates three phases of the behaviour for displaying fear in both the robot and dog.

Figure 1 

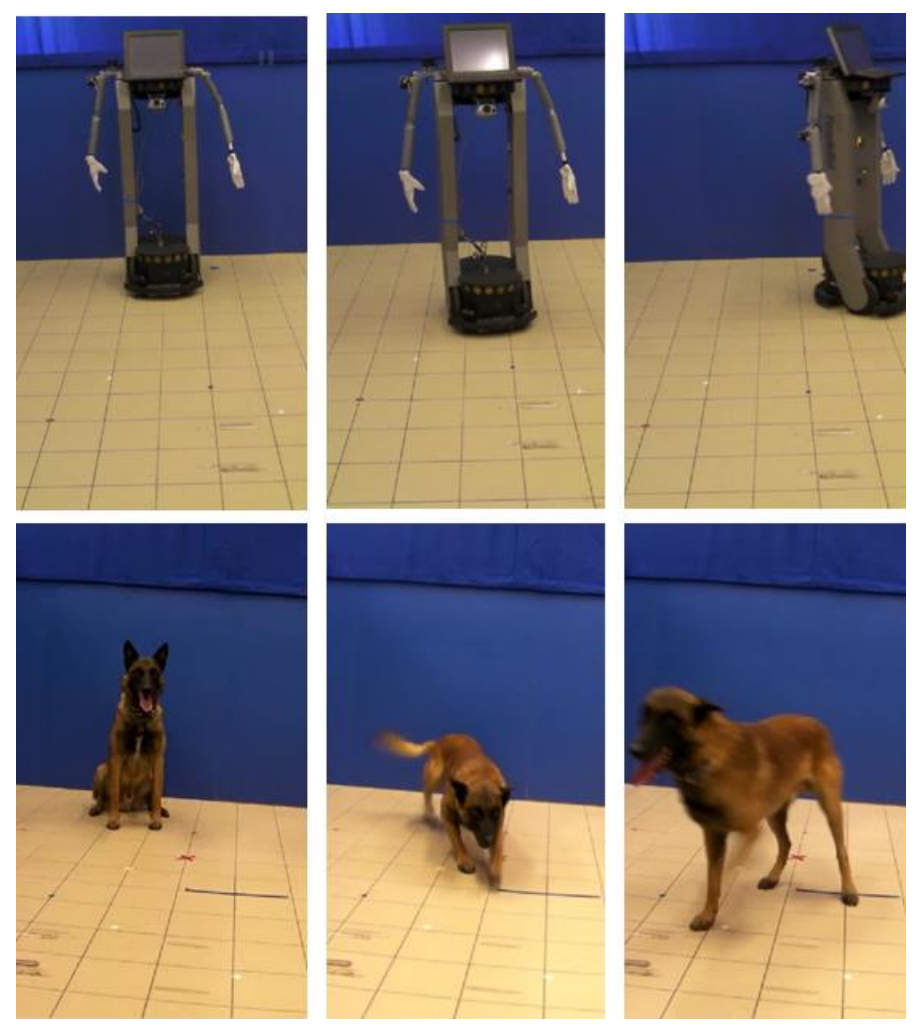

\subsection{Presentation of the videos - Questionnaire}

All participants watched 10 video clips in a row; half of them started with the five robot videos while the other half with the five dog videos. They watched the videos in six small groups $(N=11-17$ / group). During the viewing of the videos an experimenter was always present in order to confirm that participant complied with the rule of not discussing the task. The clips presenting different emotions within the dog and robot blocks were presented in one of six quasi-random orders.

Participants watched the whole series of the 10 video clips twice in the same order. During the first viewing they were asked to complete the open-ended questionnaire and on the second occasion they answered multiple choice questions. In both cases participants had to evaluate the records one by one, watching each video clip separately.

Before the first viewing participants received no information about the aim of the study or what they would see. Moreover, the forced-choice questionnaires were not handed out until 
participants had completed the open-ended questions for all ten videos to avoid influencing the open ended answers by the multiple choice options.

The instruction to the open-ended questions was: "In the following you will see ten short videos. Please, write down briefly what is happening on each video!"

Participants received the multiple choice questions after completing the first part of the questionnaire. Here they could choose from the list of the five emotional states. The instruction for this part was: "Please, choose from the following inner states the one which best describes the video!" In addition, participants were asked to give a 0-4 certainty score for their choice.

\subsection{Data analysis}

\subsubsection{Open-ended questions}

We scored the answers for the open-ended questions depending on how directly they referred to some emotional/mental state. The participant received:

1 point if s/he wrote a formal description of the observed behaviour (e.g., comes closer, raises its arm)

2 points if s/he indicated some contextual behaviour attributing a meaning to the video that cannot be directly observed from the behaviour of the agent (e.g., greets someone, waters the plants)

3 points if s/he mentioned a term or phrase, which implicitly indicated some inner state but without naming that concrete emotion (e.g., threatens somebody, tries to escape)

4 points if s/he named an inner state or emotion explicitly either as a verb, a noun or an adjective (e.g. happy, it is afraid of something).

Inter-observer agreement (Cohen's kappa) for the categorisation, calculated from the double scoring of six questionnaires (altogether 60 questions) by a second coder who was not part of the project was almost perfect: 0.84 (based on guidelines by Landis and Koch, 1977). 
Based on the result of Shapiro-Wilk test and visual inspection of the Q-Q plots we run a repeated measures ANOVA to test the effect of the experience with dogs and order of presentation (dog first vs. robot first) as between subject factors on the mean scores of the dog and robot video clips (within subject factor). Then we tested if scores for the emotionally loaded videos (average scores for the videos of anger, fear, joy, sadness) differed from the scores of the neutral video in case of both the dog and the robot with Wilcoxon tests (because the scores for the neutral video did not follow normal distribution).

If participants named an emotion or a behaviour that indicated it (points 3 or 4), we also analysed whether their answer was correct or not, and compared it to the success rate in the multiple-choice questions (paired-samples t-test).

\subsubsection{Multiple-choice questions}

We first compared the rate of correct choices for each video clip to chance level (binomial test, chance level 0.2).

Next, we analysed the effect of three factors; the agent performing the given emotion (dog vs. robot), the human participants' experience with dogs (owner vs. non-owner), and the order of the presentation of the videos (dog first vs. robot first) as main effects, and also their two way interactions on the viewers' success by Generalized Linear Mixed Models with binomial distribution and logit link. To simplify our model, we applied p-value based model selection, leaving out one-by-one the least significant interactions till only significant $(\mathrm{p}<0.05)$ ones remained.

Average certainty ratings for dog vs. robot videos were compared with paired samples ttest. The relation between certainty ratings and the proportion of correct responses was tested by Pearson correlation, while the difference in the certainty ratings of correctly vs. incorrectly assessed videos was compared by paired-samples t-test. 


\subsubsection{Comparing the results of the two types of questions}

We compared the rate of the correct answers to the open-ended questions (in those cases when participants characterized the videos with an emotion or with a behaviour indicating an inner state: scores 3 or 4 ) with the rate of the correct answers in the multiple-choice part of the questionnaire using paired t-test.

We applied Benjamini \& Hochberg corrections for multiple comparisons, except in case of the statistical tests that controlled for multiple comparison (GLMM).

\section{Results}

\subsection{Open-ended questionnaire}

Participants tended to spontaneously attribute emotions (gave score 3 or 4) to both the robot (12-57\%, depending on the emotion) and the dog (31-68\%, depending on the emotion)

(Figure 2.). They gave higher scores to the dog (mean $=2.52, \mathrm{SD}=0.44)$ than to the robot $($ mean $=2.09, \mathrm{SD}=0.56)$ video clips $\left(F_{(1,74)}=47.57, p<0.001\right)$. Neither the order of presentation (robot or dog videos first) $\left(F_{(1,74)}=1.18, p=0.282\right)$ nor the experience with dogs $\left(F_{(1,74)}=0.88, p=0.351\right)$ had an effect on attributing emotions.

Participants $(N=78)$ gave higher scores in case of the videos depicting emotions (mean emotion score for anger, fear, joy, sadness), than in case of the neutral video both in case of the $\operatorname{dog}(Z=-5.809, p<0.001)$ and the $\operatorname{robot}(Z=-5.58, p<0.001)$.

Figure 2 


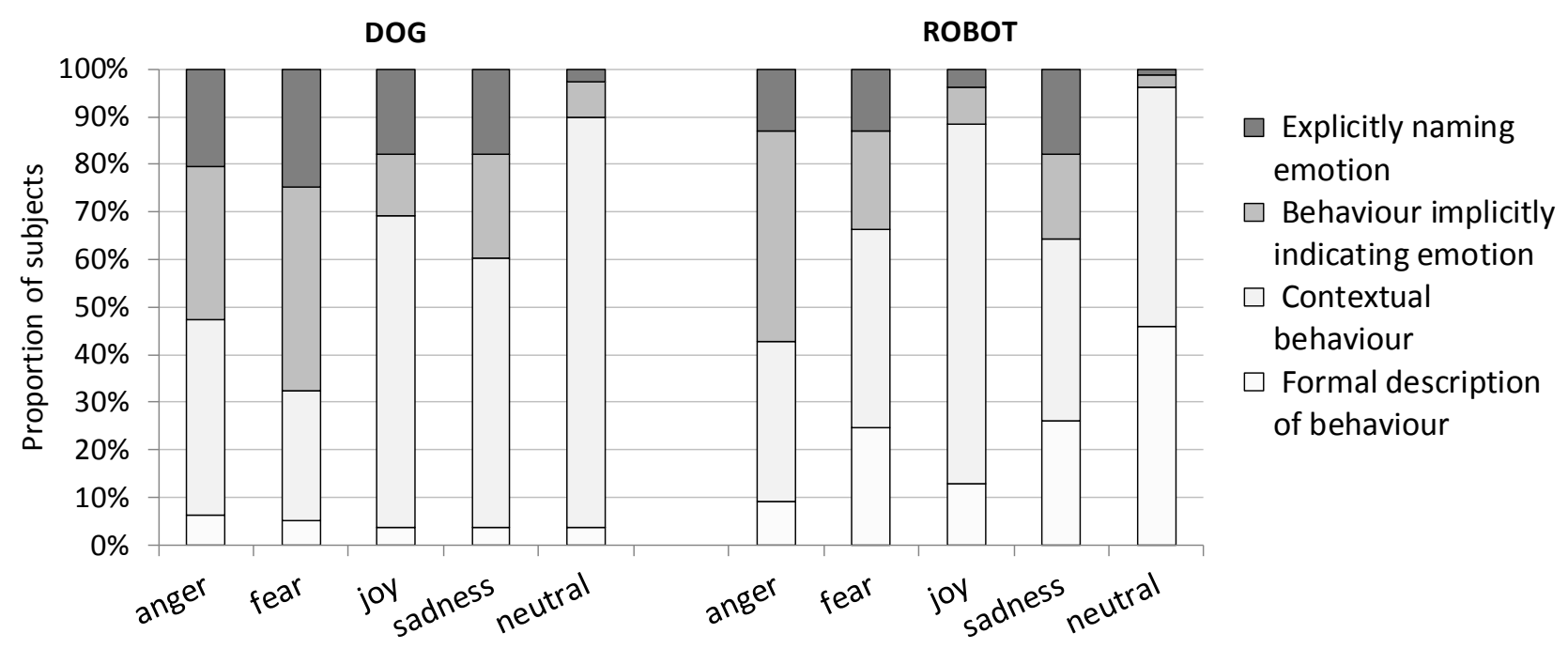

3.1.1. Multiple-choice questions

Participants $(N=81)$ could successfully choose the correct emotional state from the five possible options; they could identify all $\operatorname{dog}$ (all $p<0.001$ ), and all robot (all $p<0.001$ ) videos above chance level. Their average success in identifying emotions was high both in the case of the dog $($ mean $=0.78, \mathrm{SD}=0.19)$; and the robot $($ mean $=0.75, \mathrm{SD}=0.22)$.

After removing non-significant interactions the Generalized Linear Mixed Model showed that experience with dogs did not have an effect $\left(F_{(1,157)}=1.24, p=0.267\right)$ and there was no difference depending on whether the dog or the robot displayed the emotions $\left(F_{=(1,157)}=1.99\right.$, $p=0.16)$. We revealed significant interaction between the order of the presentations and the identity of the actor (dog/robot) $\left(F_{(1,157)}=4.16, p=0.043\right)$ and the effect of the order $\left(F_{(1,157)}\right.$ $=5.23, p=0.024)$. The post hoc analysis showed that participants that saw the dog videos first were better at identifying the robot videos afterwards $\left(F_{(1,157)}=9.67, p=0.002\right)$, while the order of the presentation had no effect in the case of the dog videos $\left(F_{(1,157)}=0.01, p=\right.$ 0.922).

Figure 3 


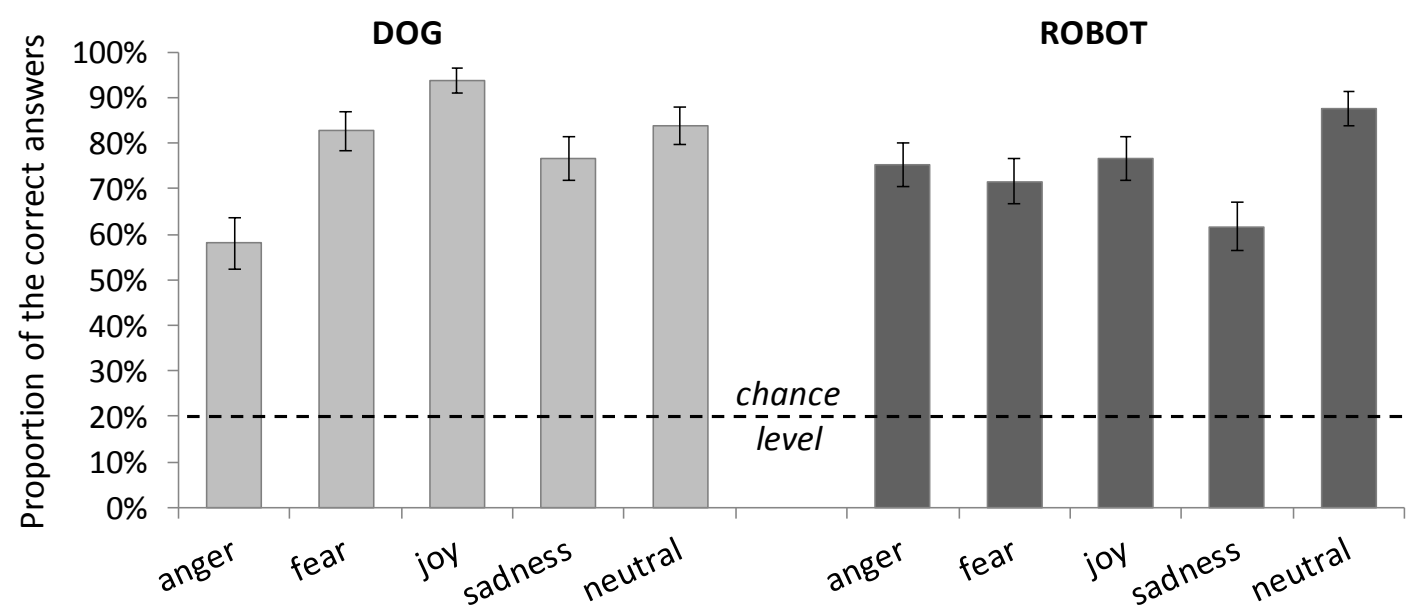

To exclude the impact of watching dog videos first, we separately analysed the data of participants who started with the robot videos. They also could identify all dog (all $p<0.001$ ), and all robot (all $p<0.001$ ) videos above chance level, however, they were better in identifying dog videos than robot videos $(Z=-2.24, p=0.025)$.

\subsubsection{Error pattern and certainty ratings}

The error pattern for each video clip was separately analysed in order to unfold the typical differences between the aimed and perceived emotions. Although 'anger' was sometimes mixed up with 'joy' both in the case of the dog and robot, the reverse situation never occurred. In the case of the robot, the most common false response for 'sadness' was 'fear', while instead of 'fear' it was 'neutral'. (Table 2)

Table 2

\begin{tabular}{|l|c|c|c|c|c|c|c|c|c|c|}
\hline \multirow{2}{*}{$\begin{array}{c}\text { Choice } \\
(\%)\end{array}$} & \multicolumn{5}{|c|}{ DOG videos } & \multicolumn{5}{c|}{ ROBOT videos } \\
\cline { 2 - 12 } & anger & fear & joy & sadness & neutral & anger & fear & joy & sadness & neutral \\
\hline anger & $\mathbf{5 8}$ & 0 & 0 & 0 & 1 & $\mathbf{7 5}$ & 0 & 0 & 1 & 7 \\
\hline fear & 22 & $\mathbf{8 3}$ & 0 & 7 & 1 & 0 & $\mathbf{7 2}$ & 1 & 26 & 0 \\
\hline joy & 19 & 9 & $\mathbf{9 4}$ & 1 & 14 & 22 & 0 & $\mathbf{7 7}$ & 4 & 2 \\
\hline sadness & 0 & 4 & 0 & $\mathbf{7 7}$ & 0 & 0 & 4 & 0 & $\mathbf{6 2}$ & 2 \\
\hline neutral & 1 & 5 & 6 & 15 & $\mathbf{8 4}$ & 2 & 25 & 22 & 7 & $\mathbf{8 8}$ \\
\hline
\end{tabular}


The overall certainty ratings of the participants were not related to the percent of correct responses $(r=0.11, p=0.318)$, but within individual participants the correctly identified videos $($ mean $=2.85, \mathrm{SD}=0.54)$ received higher certainty ratings $\left(t_{(69)}=4.55, p<0.001\right)$ than incorrectly identified ones (mean $=2.5, \mathrm{SD}=0.65$ ). Participants also gave higher certainty ratings for dog $($ mean $=2.93, \mathrm{SD}=0.56)$ than for robot $($ mean $=2.6, \mathrm{SD}=0.64)$ videos $(t(80)$ $=4.60, p<0.001)$.

\subsection{Correspondence of the responses to the open-ended and multiple choice questions}

First we selected those who not only named an emotion or behaviour that was characteristic to an inner state (scores 3 and 4) in the open ended questionnaire, but their answers were correct. Then we compared the occurrence of these answers with the occurrence of the correct answers in the multiple-choice part of the questionnaire. We found that participants could identify the emotions equally well answering the two types of questions both in case of the $\operatorname{dog}\left(t_{(67)}=0.27, p=0.787\right)$ and the $\operatorname{robot}\left(t_{(56)}=1.13, p=0.264\right)$.

\section{Discussion}

The main aim of this study was to investigate whether humans attribute emotions to a robot that performs simple actions inspired by dog expressive behaviours. The embodiment of the dog has been used as a starting point for designing emotional behaviour for any social robot considering it less likely that near-future robots will be able to display minute aspects of human emotional behaviour without very expensive and complicated hardware and software.

As a first step toward testing our general suggestion of using the dog as a behavioural model, we used one specific robot, a PeopleBot, which was remarkably different from both humans and dogs with regard to its appearance and abilities. The lack of social contextual cues helped to ensure that viewers were restricted to evaluate the displays of the robot and the dog. 
First we showed that although we did not refer to the aim of the study or mentioned emotions in any way, participants tended to interpret the actions of the robot by crediting it with different - mainly correct - emotions. As expected, participants attributed inner states more often to the dog than to the robot, however, they could clearly distinguish emotionally loaded and neutral states also in case of the robot. Obviously, these results should be interpreted within the conditions applied in the present study, and should not be compared to real life situations in which several factors, specifically the context facilitates attribution. There is evidence that, for example, observing the behaviour of another person towards a vacuum cleaning robot, influences participants' physiological responses of compassion (Hoenen, Lübke, \& Pause, 2016). Considering that during long term exposure to a robot (e.g. de Graaf, Allouch, \& Klamer, 2015), learning may occur making participants better at recognizing emotions, it is important to note that no effect of experience with dogs was found in the present study. Lower rates of emotion attribution are often found in similar, relatively artificial experimental situations (Barrett, Mesquita, \& Gendron, 2011). Moreover, we cannot expect perfect recognition of emotional states in robot-human encounters as there is no perfect success rate even in the case of human facial expressions, especially when open ended questions are used (Haidt \& Keltner, 1999). It is interesting to mention, however, that a priming effect occurred for the multiple choice questions: viewing the dog videos first helped identifying the correct emotions of the robot videos probably by making the participants aware of the two agents performing the same behavioural patterns and/or realizing that the videos are about emotion expression.

In the result section we referred to choices that corresponded to the ones we aimed to display as "correct" answers, but we should not forget that from the viewpoint of robot development, participants' (i.e. potential users') impressions by definition cannot be false. On the contrary, their subjective evaluation can best validate the robot's expressive behaviours. Therefore, we argue for the importance of using both open-ended questionnaires and non- 
contextual test situations, because participants' spontaneous impressions can serve as the most convincing evidence to validate the believability and distinctness of robot expressive behaviours (when direct interaction with the robot is not possible). Thus we claim that both the attribution of no emotions (except in the neutral state) and the attribution of "incorrect" emotions mean that the actions of the robot have not been properly set.

In the multiple-choice part participants identified all 10 video clips significantly better than chance. So far the expressive behaviours of social robots in user studies have been evaluated mainly by testing the recognition of the robots' human-like facial expressions. For example, Saldien, Goris, Vanderborght, Vanderfaeillie, \& Lefeber (2010) compared the recognition rates of the six "basic" emotions in case of robots which have the potential to be used in robot assisted therapy. In these studies multiple-choice questionnaires were applied for the categorisation of emotions, and the robots' facial expressions were presented via photos or short video clips. The overall emotion recognition rate of the different robot faces was as follows: Probo - 73\% (Saldien et al., 2010), Kismet - 73\% (Breazeal, 2002), Eddie 57\% (Sosnowski, Bittermann, Kuhnlenz, \& Buss, 2006), and Feelix - 45\% (Cañamero \& Fredslund, 2000), which are comparable to our result with the PeopleBot $-75 \%$. The relatively less success in the recognition of some emotion displays in our experiment could be at least partly due to the fact that for practical reasons, in our set up neither the dog nor the robot could fully approach the viewer (as a dog would do in natural circumstances). We assume that by using a panoramic head-camera we can improve these success rates. However, in another study (Meints \& Keuster, 2009) it was also found that similarly to our results, participants (in that case children), intermixed the canine emotional expressions of joy and anger. Recent results about autistic children's recognition of robot emotions show that while in case of some emotions (e.g. fear) their performance is better when gestures are added to facial expressions, in case of other emotions (e.g. anger) facial expressions alone are better interpreted (Salvador, Silver, \& Mahoor, 2015). Another study found that participants showed 
the same neural activation pattern in an fMRI study towards an affectionate video of a human versus a robot, while they gave a higher neural reaction for the human compared to the robot video in the abusive context (Rosenthal-von der Pütten et al., 2014). These together with our results suggest that, apart from the design issues, there is natural variation in humans' perception of the different emotions referring to robots.

The success rate of our participants was also similar to those of previous studies on human facial expressions (Elfenbein \& Ambady, 2002) and postures or body movements (de Gelder, 2009). The high rate of emotion recognition is not surprising, as in nature bodily and facial expressions are mostly used together and they provide redundant inner state information. We should note, however, that while facial gestures are more human specific, body movements are based on more general mammalian homologues (Plutchik, 2001). This also raises the possibility that not only dogs but other companion animals (or even other mammalian social species) could be used to some extent as models for emotional expressions in social robots (see Miklósi \& Gácsi, 2012). The robotic emotional expressions based on the behaviour of different species (both humans and non-human animals) should be compared in future research in order to determine the effectiveness of the different model systems.

A potential advantage of the proposed dog model is underlined by the fact that experience with dogs did not help to evaluate the inner states presented on the videos. Similar results were reported by (Tami \& Gallagher, 2009) who found that observers of video clips did not differ in their ability to properly label dog expressive behaviour according to their experiences with dogs, and participants in general tended to give 'holistic' descriptions of dog behaviour, such as 'the dog feels...'. Regarding dog vocal signals (barking), visual experience did not play a major role in the emotion attribution of congenitally blind individuals, blind individuals with previous visual experience, and sighted individuals (Molnár, Pongrácz, \& Miklósi, 2010). On the other hand, viewing the dog videos first seemed to facilitate attribution of emotions to the robot suggesting that even if the success rate of emotion recognition was 
similar for the two agents, the dog videos still had a priming effect on the robot videos. This is further supported by the fact that participants more readily attributed emotions to the dog compared to the robot in the open-ended part of the study and that they gave higher certainty ratings for the dog videos in the forced choice task. In order to tease apart these subtle differences between attributing emotions to an animal versus an artificial agent more studies will be needed using different measures (e.g. Likert scales for the different emotions and/or physiological measures such as skin conductance, EKG, fMRI).

\section{Conclusion}

In sum, the results of the present study paved the way for more specific experiments to investigate that in what respect the dog can be a promising animal model for integrating function and sociality to develop social robots that humans perceive as more 'companionlike'. We do not want to claim that this approach leads to social robots that have comparable emotional behaviour to that of humans, but rather we aim to design a behaviour system which has the potential to provide social robots (with very basic embodiments) the maximum chance for emotion expression.

Recently, it has been suggested that the human-robot social interaction should be considered as an interspecific interaction, because such encounters take place between two individuals of different 'species', which are characterised by not only different 'anatomy' but also distinct communicational abilities (Miklósi \& Gácsi, 2012). It has also been argued that human emotions and expressive behaviours can be too complex or ambiguous to implement in simple social robots. The recognition of simple expressive behaviours can be facilitated if they are based on lower level but more general biological primitives. This way we can adjust the relevant behaviour elements to the capacities of a given robot to reach optimal expressive behaviours, without the need of adding extensive and complicated new features to the robot, which this way could fit primarily to its function. 
Our results may facilitate the emergence of a new generation of more natural robots which are equipped with ethologically more adequate behaviours, analogous to those displayed by dogs for affective communication. Importantly, we do not advocate to build robots that mimic a dog, as such attempts would constrain the behavioural repertoire and may lead to discomfort in some users (see Jones, Lawson, \& Mills, 2008). This study presented one example for the proposed methodology and calls for further experiments using different embodiments and inner states, with and without social contexts and teasing apart the potentially additive effect of different modalities in order to test the broader hypothesis. 


\section{References}

Andics, A., Gácsi, M., Faragó, T., Kis, A., \& Miklósi, Á. (2014). Voice-sensitive regions in the dog and human brain are revealed by comparative fMRI. Current Biology, 24(5), 574-578. http://doi.org/10.1016/j.cub.2014.01.058

Aviezer, H., Bentin, S., Hassin, R. R., Meschino, W. S., Kennedy, J., Grewal, S., ... Moscovitch, M. (2009). Not on the face alone: perception of contextualized face expressions in Huntington's disease. Brain, 132(Pt 6), 1633-1644. http://doi.org/10.1093/brain/awp067

Bänziger, T., Grandjean, D., \& Scherer, K. R. (2009). Emotion recognition from expressions in face, voice, and body: the Multimodal Emotion Recognition Test (MERT). Emotion, 9(5), 691-704. http://doi.org/10.1037/a0017088

Barrett, L. F., Mesquita, B., \& Gendron, M. (2011). Context in emotion perception. Current $\begin{array}{llll}\text { Directions in } \quad \text { Psychological 20(5), } & \text { 286-290. }\end{array}$ http://doi.org/10.1177/0963721411422522

Bartneck, C. (2001). How convincing is Mr. Data's smile: Affective expressions of machines. User Modeling and User-Adapted Interaction, 11, 279-295.

Bartneck, C., Reichenbach, J., \& Breemen, A. Van. (2004). In your face, robot! The influence of a character' $s$ embodiment on how users perceive its emotional expressions. In Proceedings of Design and Emotion. Ankara.

Bensky, M. K., Gosling, S. D., \& Sinn, D. L. (2013). The world from a dog's point of view: A review and synthesis of dog cognition research. In H. J. Brockmann, T. J. Roper, M. Naguib, \& L. Barrett (Eds.), Advances in the Study of Behavior (Vol. 45, pp. 209-406). Elsevier Inc.: Academic Press.

Bloom, T., \& Friedman, H. (2013). Classifying dogs' (Canis familiaris) facial expressions from photographs. Behavioural Processes. http://doi.org/10.1016/j.beproc.2013.02.010

Boersma, P., \& Weenink, D. (2014). Praat: doing phonetics by computer. Retrieved from http://www.praat.org/

Breazeal, C. (2002). Designing sociable robots. Cambridge: MIT Press.

Breazeal, C. (2003). Emotion and sociable humanoid robots. International Journal of HumanComputer Studies, 59(1-2), 119-155. http://doi.org/10.1016/S1071-5819(03)00018-1

Cañamero, L., \& Fredslund, J. (2000). How does it feel? Emotional interaction with a humanoid lego robot. In Intelligent Agents: The Human in the Loop (pp. 23-28).

Carroll, J. M., \& Russell, J. A. (1996). Do facial expressions signal specific emotions? Judging emotion from the face in context. Journal of Personality and Social Psychology, $70(2), 205-218$.

Chuenwattanapranithi, S. (2008). Encoding emotions in speech with the size code - A perceptual investigation. Phonetica, 65, 210-230.

de Gelder, B. (2009). Why bodies? Twelve reasons for including bodily expressions in affective neuroscience. Philosophical Transactions of the Royal Society of London. Series B, Biological Sciences, 364(1535), 3475-3484. http://doi.org/10.1098/rstb.2009.0190

de Graaf, M. M. A., Allouch, S. Ben, \& Klamer, T. (2015). Sharing a life with Harvey: 
Exploring the acceptance of and relationship-building with a social robot. Computers in Human Behavior, 43, 1-14. http://doi.org/10.1016/j.chb.2014.10.030

Ekman, P. (1992). An argument for basic emotions. Cognition \& Emotion, 6(3), 169-200. http://doi.org/10.1080/02699939208411068

Ekman, P. (1993). Facial expression and emotion. American Psychologist, 48(4), 376-379.

Elfenbein, H. A., \& Ambady, N. (2002). On the universality and cultural specificity of emotion recognition: A meta-analysis. Psychological Bulletin, 128(2), 203-235. http://doi.org/10.1037//0033-2909.128.2.203

Erden, M. S. (2013). Emotional postures for the humanoid-robot nao. International Journal of Social Robotics, 5(4), 441-456. http://doi.org/10.1007/s12369-013-0200-4

Faragó, T., Andics, A., Devecseri, V., Kis, A., Gácsi, M., Ádám, M., \& Miklósi, Á. (2014). Humans rely on the same rules to assess emotional valence and intensity in conspecific and dog vocalizations. Biology Letters, 10, 20130926.

Faragó, T., Miklósi, Á., Korcsok, B., Száraz, J., \& Gácsi, M. (2014). Social behaviours in dog-owner interactions can serve as a model for designing social robots. Interaction Studies, 15(2), 143-172.

Fox, M. W. (1971). Socio-infantile and socio-sexual signals in Canids: A comparative and ontogenetic study. Zeitschrift Fuer Tierpsychologie, 28(2), 185-210.

Friedman, B., Kahn, P. H., \& Hagman, J. (2003). Hardware companions ? - what online AIBO discussion forums reveal about the human-robotic relationship. In Proceedings of the SIGCHI conference on Human factors in computing systems (pp. 273-280).

Gácsi, M., Szakadát, S., \& Miklósi, Á. (2013). Assistance dogs provide a useful behavioral model to enrich communicative skills of assistance robots. Frontiers in Psychology, 4, 971. http://doi.org/10.3389/fpsyg.2013.00971

Gácsi, M., Topál, J., Miklósi, Á., Dóka, A., \& Csányi, V. (2001). Attachment behavior of adult dogs (Canis familiaris) living at rescue centers: Forming new bonds. Journal of Comparative Psychology, 115(4), 423-431. http://doi.org/10.1037//0735-7036.115.4.423

Gosling, S. D., Kwan, V. S. Y., \& John, O. P. (2003). A dog's got personality: a cross-species comparative approach to personality judgments in dogs and humans. Journal of Personality and Social Psychology, 85(6), 1161-1169. http://doi.org/10.1037/00223514.85.6.1161

Gross, M. M., Crane, E. a., \& Fredrickson, B. L. (2010). Methodology for Assessing Bodily Expression of Emotion. Journal of Nonverbal Behavior, 34(4), 223-248. http://doi.org/10.1007/s10919-010-0094-X

Haidt, J., \& Keltner, D. (1999). Culture and facial expression: Open-ended methods find more expressions and a gradient of recognition. Cognition and Emotion, 13(3), 225-226.

Hecht, J., Miklósi, Á., \& Gácsi, M. (2012). Behavioral assessment and owner perceptions of behaviors associated with guilt in dogs. Applied Animal Behaviour Science, 139(1-2), 134-142. http://doi.org/10.1016/j.applanim.2012.02.015

Hoenen, M., Lübke, K. T., \& Pause, B. M. (2016). Non-anthropomorphic robots as social entities on a neurophysiological level. Computers in Human Behavior, 57, 182-186. http://doi.org/10.1016/j.chb.2015.12.034

Ichikawa, T., Member, S., Yuki, M., Korondi, P., Member, S., Hashimoto, H., ... Niitsuma, M. (2012). Impression evaluation for different behavioral characteristics in ethologically inspired human-robot communication. In RO-MAN 2009 - The 18th IEEE International 
Symposium on Robot and Human Interactive Communication (pp. 55-60). Paris.

Jack, R. E., Garrod, O. G. B., \& Schyns, P. G. (2014). Dynamic facial expressions of emotion transmit an evolving hierarchy of signals over time. Current Biology, 24(2), 187-192. http://doi.org/10.1016/j.cub.2013.11.064

Jones, T., Lawson, S., \& Mills, D. (2008). Interaction with a zoomorphic robot that exhibits canid mechanisms of behaviour. 2008 IEEE International Conference on Robotics and Automation, 2128-2133. http://doi.org/10.1109/ROBOT.2008.4543521

Kaminski, J., Bräuer, J., Call, J., \& Tomasello, M. (2009). Domestic dogs are sensitive to a human's perspective. Behaviour, 146(7), 979-998. http://doi.org/10.1163/156853908X395530

Kätsyri, J., Klucharev, V., Frydrych, M., \& Sams, M. (2003). Identification of synthetic and natural emotional facial expressions. In International Conference on Audio-Visual Speech Processing (AVSP 2003) (pp. 3-7). St. Jorioz.

Klausz, B., Kis, A., Persa, E., Miklósi, Á., \& Gácsi, M. (2014). A quick assessment tool for human-directed aggression in pet dogs. Aggressive Behavior, 40(2), 178-188. http://doi.org/10.1002/ab.21501

Koay, K. L., Lakatos, G., Syrdal, D. S., Gácsi, M., Bereczky, B., Dautenhahn, K., ... Walters, M. L. (2013). Hey! There is someone at your door. A hearing robot using visual communication signals of hearing dogs to communicate intent. In Proceeding of the 2013 IEEE Symposium on Artificial Life (pp. 90-97). Singapore.

Konok, V., Dóka, A., \& Miklósi, Á. (2011). The behavior of the domestic dog (Canis familiaris) during separation from and reunion with the owner: A questionnaire and an experimental study. Applied Animal Behaviour Science, 135(4), 300-308. http://doi.org/10.1016/j.applanim.2011.10.011

Kovács, S., Vincze, D., Gácsi, M., Miklósi, Á., \& Korondi, P. (2009). Interpolation based fuzzy automaton for human-robot interaction. In 9th IFAC Symposium on Robot Control Nagaragawa Convention Center. Gifu, Japan.

Lakatos, G., Gácsi, M., Konok, V., Brúder, I., Bereczky, B., Korondi, P., \& Miklósi, Á. (2014). Emotion attribution to a non-humanoid robot in different social situations. PLoS ONE, 9(12), e114207. http://doi.org/10.1371/journal.pone.0114207

Lakatos, G., Janiak, M., Malek, L., Muszynski, R., Konok, V., Tchon, K., \& Miklósi, Á. (2014). Sensing sociality in dogs: what may make an interactive robot social? Animal Cognition, 17, 387-97. http://doi.org/10.1007/s10071-013-0670-7

Leite, I., Martinho, C., \& Paiva, A. (2008). Are emotional robots more fun to play with? In The 17th IEEE International Symposium (pp. 77-82).

Li, H., Yeow, J. C., \& Tan, K. (2011). Towards an effective design of social robots. International Journal of Social Robotics, 3, 333-335. http://doi.org/10.1007/s12369-0110121-z

Li, J., \& Chignell, M. (2010). Communication of emotion in social robots through simple head and arm movements. International Journal of Social Robotics, 3(2), 125-142. http://doi.org/10.1007/s12369-010-0071-X

Mara, M., \& Appel, M. (2015). Effects of lateral head tilt on user perceptions of humanoid and android robots. Computers in Human Behavior, 44, 326-334. http://doi.org/10.1016/j.chb.2014.09.025

Meeren, H. K. M., van Heijnsbergen, C. C. R. J., \& de Gelder, B. (2005). Rapid perceptual 
integration of facial expression and emotional body language. Proceedings of the National Academy of Sciences of the United States of America, 102(45), 16518-16523. http://doi.org/10.1073/pnas.0507650102

Meints, K., \& Keuster, T. De. (2009). Don't kiss a sleeping dog: The first assessment of "'The Blue Dog"” bite prevention program. Journal of Pediatric Psychology, 34(10), $1084-1090$.

Merola, I., Prato-Previde, E., \& Marshall-Pescini, S. (2012). Dogs' social referencing towards $\begin{array}{lllll}\text { owners and } \quad \text { strangers. } & \text { PLoS } 47653 .\end{array}$ http://doi.org/10.1371/journal.pone.0047653

Miklósi, Á., \& Gácsi, M. (2012). On the utilisation of social animals as a model for social robotics. Frontiers in Psychology, 3, 75. http://doi.org/10.3389/fpsyg.2012.00075

Miklósi, Á., Polgárdi, R., Topál, J., \& Csányi, V. (2000). Intentional behaviour in dog-human communication: an experimental analysis of "showing" behaviour in the dog. Animal Cognition, 3(3), 159-166. http://doi.org/10.1007/s100710000072

Miklósi, Á., \& Topál, J. (2013). What does it take to become "best friends"? Evolutionary changes in canine social competence. Trends in Cognitive Sciences, 17(6), 287-294. http://doi.org/10.1016/j.tics.2013.04.005

Molnár, C., Pongrácz, P., \& Miklósi, Á. (2010). Seeing with ears: Sightless humans' perception of dog bark provides a test for structural rules in vocal communication. Quarterly Journal of Experimental Psychology, 63(5), 1004-1013. http://doi.org/10.1080/17470210903168243

Morell, V. (2009). Going to the dogs. Science, 325, 1062-1065.

Morris, P., Doe, C., \& Godsell, E. (2008). Secondary emotions in non-primate species? Behavioural reports and subjective claims by animal owners. Cognition \& Emotion, 22(1), 3-20. http://doi.org/10.1080/02699930701273716

Morris, P., Fidler, M., \& Costall, A. (2000). Beyond anecdotes: An empirical study of "anthropomorphism." Society and Animals, 8(2), 151-165. http://doi.org/10.1163/156853000511050

Morton, E. S. (1977). On the occurrence and significance of motivation-structural rules in some bird and mammal sounds. The American Naturalist, 111(981), 855-869. Retrieved from http://www.jstor.org/stable/2460385

Petisca, S., Dias, J., \& Paiva, A. (2014). More Social and Emotional Behaviour May Lead to Poorer Perceptions of a Social Robot. 6th International Conference, ICSR 2014, Proceedings, 412. http://doi.org/10.1007/978-3-319-11973-1

Pineau, J. (2003). Towards robotic assistants in nursing homes: Challenges and results. Robotics and Autonomous Systems, 42(3-4), 271-281. http://doi.org/10.1016/S09218890(02)00381-0

Plutchik, R. (2001). The nature of emotions. American Scientist, 89, 344.

Plutchik, R. (2001). The nature of emotions. Human emotions have deep evolutionary roots, a fact that may explain their complexity and provide tools for clinical practice. American Scientist, 89(4), 344-350.

Pongrácz, P., Molnár, C., Dóka, A., \& Miklósi, Á. (2011). Do children understand man's best friend? Classification of dog barks by pre-adolescents and adults. Applied Animal Behaviour Science, 135, 95-102. http://doi.org/10.1016/j.applanim.2011.09.005

Pongrácz, P., Molnár, C., \& Miklósi, Á. (2006). Acoustic parameters of dog barks carry 
emotional information for humans. Applied Animal Behaviour Science, 100(3-4), 228240. http://doi.org/10.1016/j.applanim.2005.12.004

Pongrácz, P., Molnár, C., Miklósi, Á., \& Csányi, V. (2005). Human listeners are able to classify dog (Canis familiaris) barks recorded in different situations. Journal of Comparative Psychology, 119(2), 136-144.

Rosenthal-von der Pütten, A. M., Schulte, F. P., Eimler, S. C., Sobieraj, S., Hoffmann, L., Maderwald, S., ... Krämer, N. C. (2014). Investigations on empathy towards humans and robots using fMRI. Computers in Human Behavior, 33, 201-212. http://doi.org/10.1016/j.chb.2014.01.004

Saldien, J., Goris, K., Vanderborght, B., Vanderfaeillie, J., \& Lefeber, D. (2010). Expressing emotions with the social robot Probo. International Journal of Social Robotics, 2(4), 377-389. http://doi.org/10.1007/s12369-010-0067-6

Salvador, M. J., Silver, S., \& Mahoor, M. H. (2015). An Emotion Recognition Comparative Study of Autistic and Typically-Developing Children using the Zeno Robot, 6128-6133. http://doi.org/10.1109/ICRA.2015.7140059

Severinson-Eklundh, K., Green, A., \& Hüttenrauch, H. (2003). Social and collaborative aspects of interaction with a service robot. Robotics and Autonomous Systems, 42(3-4), 223-234. http://doi.org/10.1016/S0921-8890(02)00377-9

Soproni, K., Miklósi, Á., Topál, J., \& Csányi, V. (2002). Dogs' (Canis familiaris) responsiveness to human pointing gestures. Journal of Comparative Psychology, 116(1), 27-34. http://doi.org/10.1037//0735-7036.116.1.27

Sosnowski, S., Bittermann, A., Kuhnlenz, K., \& Buss, M. (2006). Design and evaluation of emotion-display EDDIE. 2006 IEEE/RSJ International Conference on Intelligent Robots and Systems, 3113-3118. http://doi.org/10.1109/IROS.2006.282330

Syrdal, D. S., Koay, K. L., Gácsi, M., Walters, M. L., \& Dautenhahn, K. (2010). Video prototyping of dog-inspired non-verbal affective communication for an appearance constrained robot. In 9th IEEE International Symposium on Robot and Human Interactive Communication. Viareggio, Italy.

Tami, G., \& Gallagher, A. (2009). Description of the behaviour of domestic dog (Canis familiaris) by experienced and inexperienced people. Applied Animal Behaviour Science, 120(3-4), 159-169. http://doi.org/10.1016/j.applanim.2009.06.009

Topál, J., Miklósi, Á., Csányi, V., \& Dóka, A. (1998). Attachment behavior in dogs (Canis familiaris): A new application of Ainsworth's (1969) Strange Situation Test. Journal of Comparative Psychology, 112(3), 219-229.

Topál, J., Miklósi, Á., Gácsi, M., Dóka, A., Pongrácz, P., Kubinyi, E., .. Csányi, V. (2009). The dog as a model for understanding human social behavior. Advances in the Study of Behavior, 39, 71-116. http://doi.org/10.1016/S0065-3454(09)39003-8

Turcsán, B., Range, F., Virányi, Z., Miklósi, Á., \& Kubinyi, E. (2012). Birds of a feather flock together? Perceived personality matching in owner-dog dyads. Applied Animal Behaviour Science, 140, 154-160. http://doi.org/10.1016/j.applanim.2012.06.004

Valsecchi, P., Previde, E. P., Accorsi, P. A., \& Fallani, G. (2010). Development of the attachment bond in guide dogs. Applied Animal Behaviour Science, 123(1-2), 43-50. http://doi.org/10.1016/j.applanim.2009.12.012

Vas, J., Topál, J., Gácsi, M., Miklósi, Á., \& Csányi, V. (2005). A friend or an enemy? Dogs’ reaction to an unfamiliar person showing behavioural cues of threat and friendliness at different times. Applied Animal Behaviour Science, 94(1-2), 99-115. 
http://doi.org/10.1016/j.applanim.2005.02.001

Wallbott, H. G. (1998). Bodily expression of emotion, 896(November 1997).

Waller, B. M., Bard, K. a, Vick, S.-J., \& Smith Pasqualini, M. C. (2007). Perceived differences between chimpanzee (Pan troglodytes) and human (Homo sapiens) facial expressions are related to emotional interpretation. Journal of Comparative Psychology, 121(4), 398-404. http://doi.org/10.1037/0735-7036.121.4.398

\section{Figure legend}

\section{Table 1}

List of the behaviours presented from the viewer's aspect for the different emotional/mental states on the videos. The first two columns describe the visual modality of the actions, the third column refers to the acoustic modality if applicable.

\section{Table 2}

Confusion matrix of the results in the case of the dog and robot video clips.

The data is given in percentage $(N=81)$. Correct choices are presented in dark grey fields, and typical incorrect choices, which were made by at least $1 / 5$ of the participants, are highlighted by light grey.

\section{Figure 1}

Characteristic screenshots from video clips showing the robot and the dog when they present behaviours related to fear (beginning, middle, and end) from the viewpoint of the experimental participants.

\section{Figure 2}


The distribution of the four categories shows in what proportion the participants characterized the dog and robot videos by giving a formal behaviour description (score 1); naming a specific, contextual behaviour (score 2); referring to a behaviour or adjective that implicitly indicates an emotion (score 3); or explicitly naming a specific emotion (4).

\section{Figure 3}

Percentage of correct answers related to each inner state in the case of the dog and the robot in the multiple-choice part of the questionnaire 